\title{
The Relationship between Head Impact Characteristics and Brain Trauma
}

\section{Blaine Hoshizaki ${ }^{1 *}$, Andrew Post ${ }^{2}$, Marshall Kendall ${ }^{2}$, Clara Karton ${ }^{2}$ and Susan Brien ${ }^{3}$}

${ }^{1}$ Neurotrauma Impact Science Laboratory, School of Human Kinetics, University of Ottawa, Canada

${ }^{2}$ School of Human Kinetics, University of Ottawa, Ottawa, Canada

${ }^{3}$ Neurosurgeon, Hull Hospital, Gatineau, Canada

\section{Introduction}

Brain injury is complex in nature and extraordinarily challenging when attempting to describe the relationship between the event and the resulting injury. In an effort to reduce its severity and incidence a great deal of research investigating mechanisms of brain injury has involved the areas of anatomical, reconstructive, and finite elements modeling. The anatomical research primarily examines functional and mechanical failure thresholds for different types of brain tissue [1-3]. Approximate strain levels are described for the different tissues that are then used to represent human responses [4]. Anatomical research examines individual brain tissues while reconstructive research simulates how injured individuals were impacted in order to discover relationships between engineering variables such as acceleration, stress, and strain and the resulting brain injury [5-7]. Currently, much of this research has focused on sporting concussions as they are frequent and often documented providing information for accurate reconstructions $[5,6]$. Finite element modeling provides a tool to obtain brain tissue response values resulting from an impact. Within the term traumatic brain injury (TBI) there are several different types of brain injury lesions, each with their own respective mechanisms and possibly predictive variables [8]. The multiple types of injuries described within TBI may also expound concussion, which has been described to have different levels of severity: sub concussive, transient, and persistent. In addition to examining the nature of the continuum of brain injury associated with the severity of impact, the mechanisms of injury contributing to these outcomes are also examined. The most common mechanisms of brain injury include: falls, collisions, projectiles, and punches. These mechanisms are examined and a synthesis of how they contribute to the outcome of the injury within the continuum of TBI and concussion is discussed. This provides information on how accelerations, resulting from an impact, affect brain tissue response and the location of the highest magnitudes of stress and strain. This review examines the nature of traumatic and concussive brain injury within the context of a continuum based upon impact severity using anatomical, reconstructive and finite element methodologies.

\section{Continuum of Brain Injury}

Historically, impacts resulting in brain injury have been separated into two broad categories: traumatic brain injury (TBI) and mild traumatic brain injury (mTBI). Within these categories are multiple types of injuries, each representing a unique injury mechanism? Traumatic brain injuries include subdural hematoma (SDH), epidural hematoma (EDH), contusion, subarachnoid hemorrhage (SAH), and diffuse axonal injury (DAI). Mild traumatic brain injury has been used synonymously with the single and common term, concussion [9]. Concussion is described with a wide variety of symptoms, recovery times, and more recently, evidence suggesting long-term neurological complications [10]. A continuum of severity for brain injury associated with impact severity has been described in traumatic brain injuries with more recent research proposing a similar continuum for mTBI $[8,11]$. It has been proposed that as there are quantifiable differences in injuries for TBI there is also likely a series of different types of injuries within mTBI, which may help explain the wide variety of symptoms associated with concussion.

\section{Traumatic Brain Injury}

Traumatic brain injury is a leading cause of death, hospitalization, and disability throughout the world. An average of 1.4 million TBIs, including 50,000 deaths occur annually in the US alone [12] from falls, road traffic accidents, sports injuries, and assaults. In Europe, the mean rate of hospitalized and fatal TBI is 235 per 100,000; more than double that of the US [13]. The direct medical costs of this type of injury, including loss of productivity have been estimated at $\$ 60$ billion annually [14]. As a result of the serious consequences of brain injuries, there has been a great deal of research investigating the mechanisms of TBI and from that, efforts to reduce its incidence. The elderly are at particular risk of TBI, especially from falls. Researchers have identified that the brain tissues and the volume of the brain changes as individuals get older $[15,16]$. The ageing process also changes how much the brain is able to displace inside the cranium [17]. With an increase in age the brain volume decreases. In addition, there is reduction of the brain tissue elasticity and deformability $[18,19]$. This can lead to situations where an impact to the head can cause strain levels on the tissue in the elderly brain that would not cause the same magnitude of injury in a younger individual.

Research investigating traumatic brain injuries has focused on developing methods to quantify the mechanism of injury using a determinant variable such as force, linear and rotational accelerations $[4,20]$. Several types of brain lesions are considered a TBI, all of which cause serious symptoms that can either, resolve if mild, or in some cases lead to death. The most commonly researched TBI lesions involve brain contusions, subdural hematoma, and diffuse axonal injury [8,21-23]. In particular, subdural hematoma and diffuse axonal injury have gained scientific attention, likely a result of their high prevalence and mortality rates. Research involving the different TBI lesions has primarily employed cadaver and animal models [24,25]. Using this approach, researchers have examined the mechanical parameters describing the kinematics of the impact (linear and rotational accelerations) reporting that subdural hematoma and diffuse axonal injury are caused by a similar mechanism involving rotational accelerations $[8,23]$. Rotations from impacts resulting in subdural hematoma create high brain-skull

*Corresponding author: Blaine Hoshizaki, Neurotrauma Impact Science Laboratory, School of Human Kinetics, University of Ottawa, A106 - 200 Lees Avenue, Ottawa, ON, Canada K1S 5S9, Tel: 613-562-5852; E-mail: thoshiza@uottawa.ca

Received September 26, 2013; Accepted December 15, 2013; Published December 27, 2013

Citation: Hoshizaki B, Post A, Kendall M, Karton C, Brien S (2013) The Relationship between Head Impact Characteristics and Brain Trauma. J Neurol Neurophysiol 5 : 181. doi:10.4172/2155-9562.1000181

Copyright: (c) 2013 Hoshizaki B, et al. This is an open-access article distributed under the terms of the Creative Commons Attribution License, which permits unrestricted use, distribution, and reproduction in any medium, provided the original author and source are credited. 
relative motion, putting a high magnitude of strain on the bridging veins that rupture [26]. In the case of DAI, high magnitude rotations cause shearing of the white matter tracts in the brain, leading to coma and often death [22]. The direction of head movement upon impact has also been associated with SDH and DAI, where antero-posterior motions cause higher strains in the brain and associated vasculature as oppose to motions in other directions [23,27]. Research involving contusions has demonstrated an association with pressure gradients, which is thought to be correlated with linear acceleration during a head impact [28]. More recent in-depth examinations of the stress and strain on the brain tissue for specific TBI lesions have described a relationship between the kinematic response of the head from impact and the resulting lesion [8]. This research focused on SDH, EDH, SAH, and contusions and reported that all types of TBI lesions resulted from short duration responses (5 ms). In addition, contusions and epidural hematoma were closely associated with linear acceleration, while SDH and SAH with rotational acceleration. As a result it has been suggested that $\mathrm{SDH}, \mathrm{SAH}$, and DAI is a more rotationally dominant injury and contusion and EDH a more linear dominant injury [8,29].

Research investigating individual sections of brain tissue has reported that the term 'traumatic brain injury' may be too general a description. Subdural hematoma, diffuse axonal injury, and contusion are three of many types of TBI lesions shown to be associated with a specific injury mechanism $[8,23]$. Recently, the authors have also postulated that while there are distinct injury mechanisms associated with types of TBI, it is likely there is also a continuum or hierarchy of injury [8,30] (Figure 1). It is proposed that not only are these injuries influenced by different mechanics of the event but also by the magnitude of the event $[8,31]$. Employing a combination of physical, computational, and finite element modeling of the human brain, reconstructions of falling incidents of varying magnitudes produced different TBI lesions supporting this theory. This research described subdural hematomas as tending to be associated with lower levels of brain deformation, followed by contusions, subarachnoid hemorrhage, and finally epidural hematoma. Interestingly, this trend was not only indicated by magnitude but also in terms of occurrence of the injury within this dataset.

\section{Concussion}

Concussions are a serious, sometimes debilitating injury that affects a large part of the population. The estimated numbers of concussions in the US alone is approximately 6 per 1000 people in the general population [32]. While TBI incur huge costs in terms of health care, it is believed that mTBI costs rival more severe head injuries when including lost work time into the equation. Typically, concussive injuries occur without sufficient mechanical brain damage to be detected using current neuro-imaging techniques. This presents unique challenges to the medical practitioners in how to diagnose and treat concussive injuries.

In the past, loss of consciousness was the primary indicator for the diagnosis of a concussion. Today, concussions are diagnosis in the absence of loss of consciousness or amnesia [33,34]. A concussion is now defined as a "complex patho-physiological process affecting the brain, induced by traumatic biomechanical forces" [34]. They typically result in the rapid onset of neural impairment, which reflects a functional rather than a structural disturbance. Impairment to the neurological function may present itself with a wide range of characteristics; including clinical symptoms, physical signs, behavioral changes, cognitive impairment, and sleep disturbance. As a result, a wide range of signs and symptoms are used to describe a concussion injury [35]. Some of the most commonly reported symptoms can be classified into four domains: somatic, physical, behavioural and cognitive [34,36]. While symptoms typically resolve over a short period of time, some cases require a lengthy period of time to fully recover [34,35,37].

Symptoms such as dizziness, nausea, and vomiting are commonly observed immediately following the impact, while persistent symptoms such as; headache, poor attention, concentration, and memory dysfunction have been reported as lasting days to weeks after sustaining a concussion [35,38]. Most concussive symptoms resolve within 3-7 days, however many cases report symptoms lasting longer than 2 weeks [39]. A similar trend was observed with patients reporting a decrease in symptomology after a one year follow-up, though the researcher cautioned that they did find that some patients were still experiencing symptoms a year after the injury [40]. There is a paucity of information pertaining to why some patients recover quickly and others continue to have symptoms that persist for months or even years. The duration of a concussion may be associated with the mechanism of injury resulting in the injury. The mechanisms of injury described in collisions, falls, punches, and projectiles have shown to characterize different levels of risk using reconstructive research [5,7,31,41]. This is consistent with anatomical testing that has also identified brain tissue to be viscoelastic, anisotropic material, exhibiting different characteristics within the various brain regions $[42,43]$. As a result, the unique loading conditions that are created from each mechanism stress the brain tissue differently depending on the event characteristics. Research has identified linear acceleration as having less influence on predicting brain stresses and strains than rotational acceleration [44-46]. This has led to increased research on rotational acceleration characteristics for the different mechanisms of injury that produce a concussion. It is probable that traumatic brain injury would occur as a result of more severe events, causing a high magnitude of brain response, such as a car crash or fall onto concrete, while mTBI injuries most likely occur from impacts events involving lower magnitudes [11] (Figure 2). Research investigating TBI has identified a continuum of severity associated with the type of lesion incurreda similar continuum for concussion may also exist (Figure 3). The most commonly used categories within the concussion group that could reflect such a continuum include: persistent concussive syndrome (PCS), transient concussion, and sub concussive impacts.

\section{Persistent concussive syndrome}

Persistent concussive syndrome (PCS) includes those with the

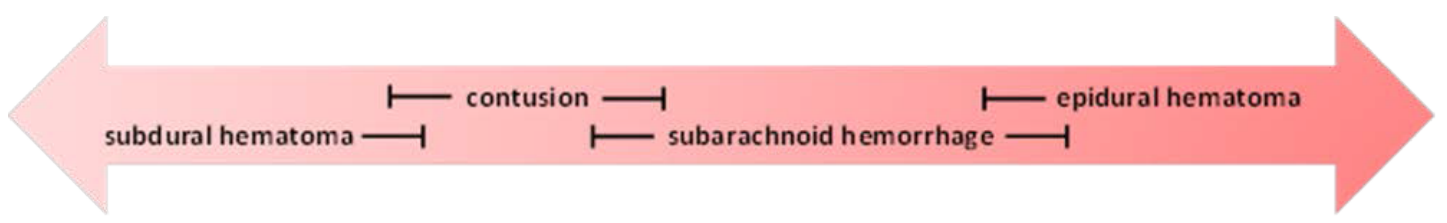

Figure 1: Depiction of the continuum of brain injury for TBI. 
Citation: Hoshizaki B, Post A, Kendall M, Karton C, Brien S (2013) The Relationship between Head Impact Characteristics and Brain Trauma. J Neurol Neurophysiol 5: 181. doi:10.4172/2155-9562.1000181

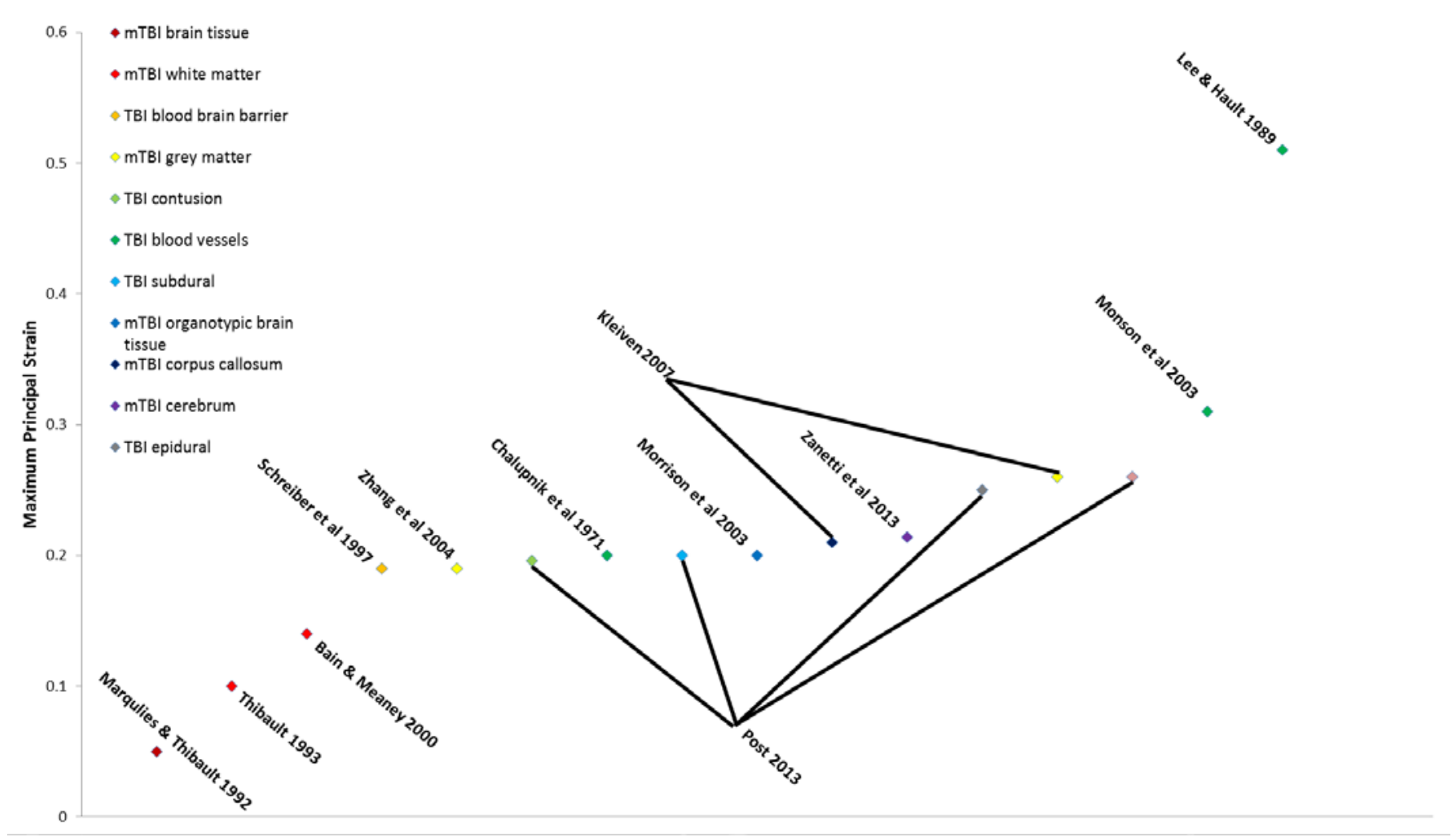

Figure 2: Continuum of brain injury in strain, showing anatomical and reconstructive research results for concussion through to TBI.

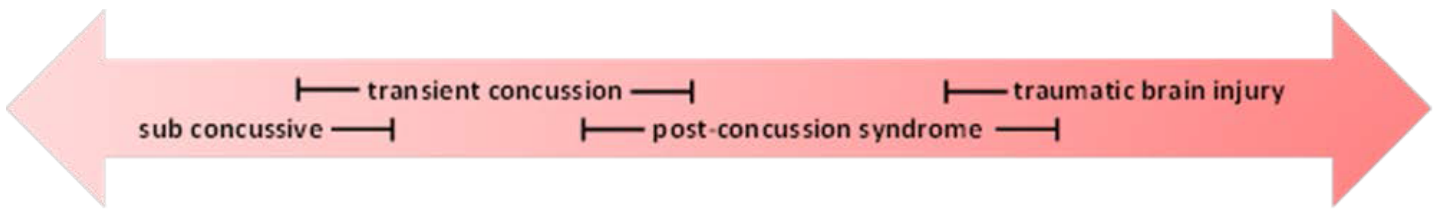

Figure 3: Depiction of the continuum of brain injury from concussion to TBI.

most severe and long lasting symptoms $[35,47,48]$. PCS has been defined as experiencing symptoms of concussion that last either one month, six months or longer, depending on the definition $[40,49]$. It is not yet fully understood why some patients suffer PCS while others experience transient symptoms. It has been proposed that this may reflect a continuum of injury for concussion [11]. Research involving complex reconstructions of concussive injuries involving sport and daily activities have shown that in many instances PCS is associated with events involving impacts with high linear and rotational acceleration values [11], or with long time histories $(>20$ ms) [50]. These parameters (magnitude and duration) are largely affected by impact characteristics, including velocity, location, mass, compliance, and vector $[7,31,41]$. These characteristics contribute to high magnitude, low duration events as would be seen in falls $[8,51]$, or lower magnitude, long duration events that would be common in football or ice hockey impacts as a result of the helmets and padding. Both these scenarios have been shown to cause a concussion associated with PCS [11,50] (Table 1 and Figure 4).

\section{Transient}

A concussion is typically identified as transient when the symptoms resolve within 14 days [39]. Transient concussions are common within sports such as ice hockey and American football $[52,53]$. On the continuum of severity, transient concussion tends to occur at magnitudes of brain stress and strain that are lower than those incurred during a PCS or TBI impact [11]. This may contribute to the transient nature of the concussion; the impact does not produce large enough tissue damage to induce a long-term symptomology. In many cases, reconstructive research has shown that transient concussion cases involve a protective helmet, but this may be reflective of the commonality of concussion within contact sports requiring head protection [5,6]. Without the presence of the helmet the impact conditions (compliance, velocity, etc.) would likely have resulted in magnitudes of response associated with TBI [54]. However, with the introduction of the helmet, the brain strain magnitudes are reduced to where concussion is a more expected outcome. In sport one of the determining factors between the occurrence of a transient, PCS concussion, or TBI may be related to the duration and magnitude of the impact event.

\section{Sub-concussive}

Sub concussive injuries have been described as impacts that result 
Citation: Hoshizaki B, Post A, Kendall M, Karton C, Brien S (2013) The Relationship between Head Impact Characteristics and Brain Trauma. J Neurol Neurophysiol 5: 181. doi:10.4172/2155-9562.1000181

\begin{tabular}{|l|c|}
\hline Impact condition & Maximum principal strain \\
\hline High compliance & $0.36(0.03)$ \\
\hline Low compliance & $0.30(0.03)$ \\
\hline
\end{tabular}

Table 1: The peak maximum principal strain resulting from a high and low compliance impact condition.

in no, or very brief symptoms of concussion [55]. The authors of this paper would contend that these impacts reflect the lowest level of trauma related to concussion, meaning they are considered concussive impacts, not sub concussive. This theory is similar in nature to what is currently being discovered concerning traumatic brain injuries, where subdural hematoma, contusion, and epidural hematoma are all TBI, but have different thresholds and mechanisms $[8,29]$. In that regard, PCS, transient, and sub concussive injuries may all be categorized as concussions, but simply reflect different magnitudes, and mechanisms of injury. Research involving impacts that are representative of sub concussive events have reported strain levels of 5-15\%, which are associated with functional impairment of the transmission of signals through neural tissue but no mechanical damage $[1,41,42,56]$. This anatomical research has demonstrated a temporary interruption of signals at low strains, which athletes may not report as concussions.
While there are a number of large impacts in contact sports such as ice hockey and American football, players are frequently exposed to smaller impacts, likely in the region of $10 \%$ strain [41]. It is the accumulation of these impacts that may be associated with known neurological degenerative diseases such as chronic traumatic encephalopathy (CTE) that affects many athletes long after retirement [10].

\section{Mechanism of Brain Injury}

It is well established in the literature that collisions involving the head are characterized by combinations of linear and rotational motion causing a cascade of physical tissue deformations and physiological responses $[9,20]$. The principle mechanism of injury associated with linear acceleration has been related to pressure gradient changes within the skull, while rotational accelerations of the head have been associated with shear stresses of the brain tissue [44,57]. Recent research identified the most common mechanisms of injury for TBI and concussion in sport involves: falling, collisions, punches, and projectiles [31]. Each of these mechanisms create unique impact conditions that influence the direction and magnitude of the head kinematic response, and subsequent brain tissue stresses and strains [58,59]. The resulting brain injury caused by these dynamic loads is influenced by the impact
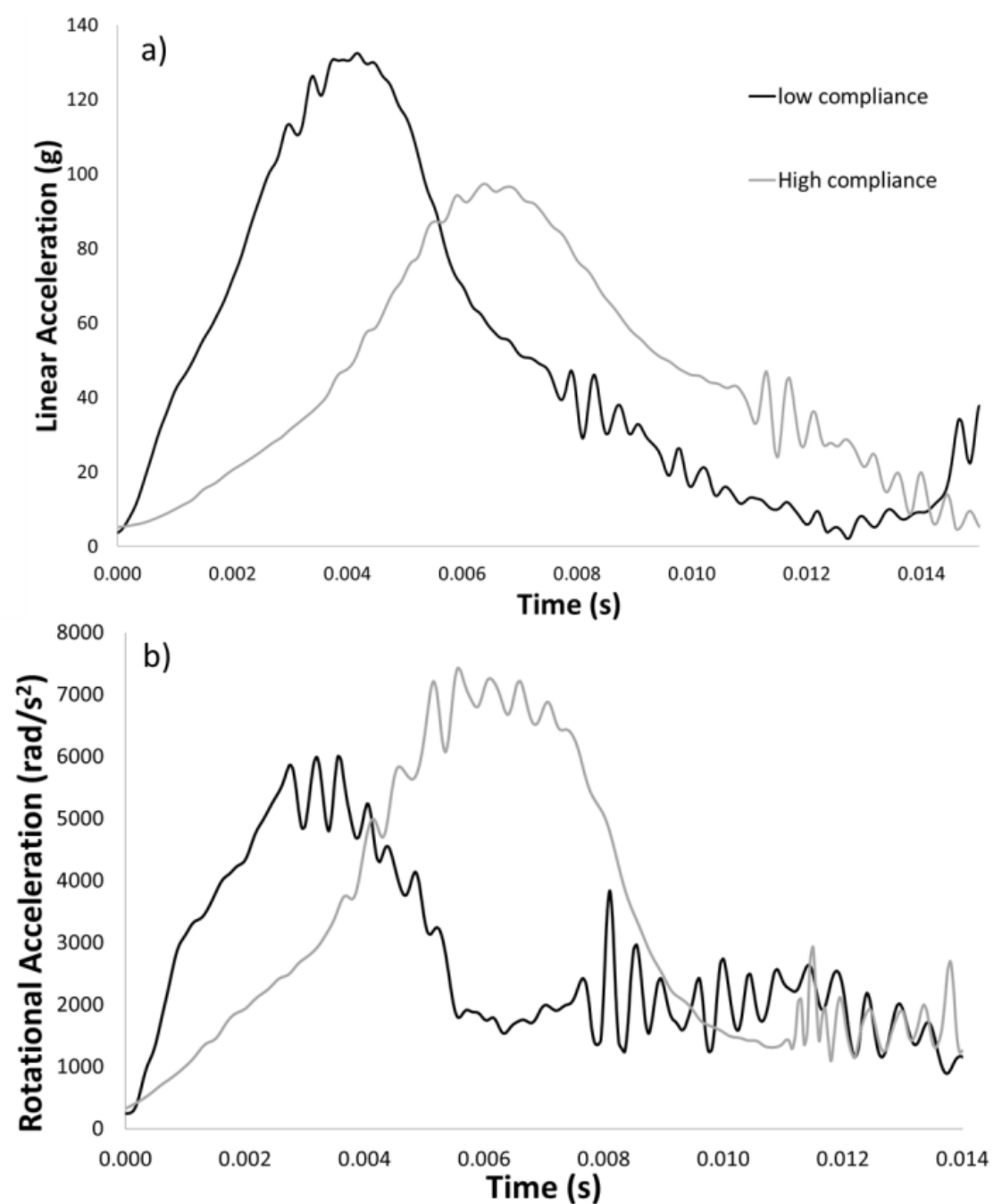

Figure 4: Depicts the dynamic response curves, peak linear acceleration (a), and peak rotational acceleration (b), for a low (short duration) and high (long duration) compliance impact at $6.5 \mathrm{~m} / \mathrm{s}$. 
Citation: Hoshizaki B, Post A, Kendall M, Karton C, Brien S (2013) The Relationship between Head Impact Characteristics and Brain Trauma. J Neurol Neurophysiol 5: 181. doi:10.4172/2155-9562.1000181

characteristics involved in the event such as impact location, mass, velocity, compliance of the surface (stiffness), and impact vector. How individual impact parameters effect the resulting brain stress and strain is important in determining the predictive characteristics of severity and type of head injury.

It is only recently that research has begun to identify particular mechanisms for brain injuries. In sports, the most common impacts causing brain injury involve falls to the ground (or rigid surface) or body segments hitting the head $[60,61]$. It is common in ice hockey and American football to observe body checks or tackles involving head to head or shoulder/elbow to head impacts [62-66]. Ice hockey also has a unique distinction within their rules where fighting is permitted at the junior and pro levels, this is reported to increase the likelihood of a player sustaining a concussion [67]. Combat sports, such as boxing and mixed martial arts, involve impacts to the head that often lead to concussive injuries [68,69]. Projectile related brain injuries are common within sports such as baseball (balls) and ice hockey (pucks). These four injury mechanisms can also be seen within everyday life, where the highest incidence of brain injury in the general population result from falls.

\section{Falls}

Falls are the most common mechanism of brain injury in the population [70,71]. This type of injury often occurs as a result of a loss of balance or slipping. The elderly in particular are at higher risk of sustaining a TBI from falling [71]. In 2003/04 the Canadian Institute for Health Information reported that of all cases, youth had the highest proportion of TBI hospitalizations as a result of falls, with elderly $(65+)$ second at $29 \%$. The high incidence of TBI in youth stems from high risk activities, while for the elderly it is likely from the inability to correct oneself and prevent a fall from a loss of balance. The ability to brace oneself during the fall can often mean the difference between a mild or serious injury. Falls typically result in impacts with high magnitude and short duration linear and rotational acceleration $[7,8]$ (Table 2 and Figure 5). This is a reflection of the low compliance of the impact surfaces commonly involved (i.e. concrete, ice). As the falling mechanism creates a high magnitude and short duration linear and rotational acceleration pulse through the brain tissue, most frequently TBI results from this type of impact event. Often the determinant between incurring a concussion rather than TBI from a fall is whether another body part (i.e. arms, leg, and shoulder) impacts the ground first, reducing the impact energy to the head. The high magnitudes of acceleration response of the head from falling also make persistent concussive syndrome a risk for this mechanism of injury [11].

\section{Collisions}

Collisions are an integral part of many sporting environments and common in everyday life [5]. Depending on the nature of the collision, a variety of impact masses can be involved, as created by the body segment in contact with the head; arm, shoulder, elbow, or leg [31]. Collisions in sport involve a wide variety of impact velocities with the higher velocity impacts resulting in concussion. Helmets are designed to reduce the magnitude of the impact and lengthen the duration of the linear and rotational acceleration pulses (Figure 5) as a result traumatic brain injuries are uncommon in sport [72]. The combination of protective equipment, (increasing compliance), varying striking mass, and higher velocities, combine to produce longer impact events. These characteristics produce impacts that are more closely associated with increased risk of concussions decreasing the risk of traumatic brain injuries (Table 2). As a result of these longer duration accelerations

\begin{tabular}{|c|c|c|c|}
\hline & \multicolumn{2}{|c|}{ Peak resultant acceleration } \\
\hline Mechanism & Linear $(\mathbf{g})$ & Rotational (rad/s $\mathbf{s}^{2}$ \\
\hline Ice & $264.4(33.8)$ & $11204(1867)$ \\
\hline Shoulder & $112.5(8.6)$ & $9659(728.5)$ & $0.424(0.019)$ \\
\hline Punch & $87.9(9.8)$ & $14001(1003)$ & $0.305(0.011)$ \\
\hline Projectile (puck) & $105.6(14.6)$ & $12187(2104)$ & $0.229(0.003)$ \\
\hline
\end{tabular}

Table 2: Peak resultant dynamic response per impact mechanism with associated MPS within the brain. [25,69].
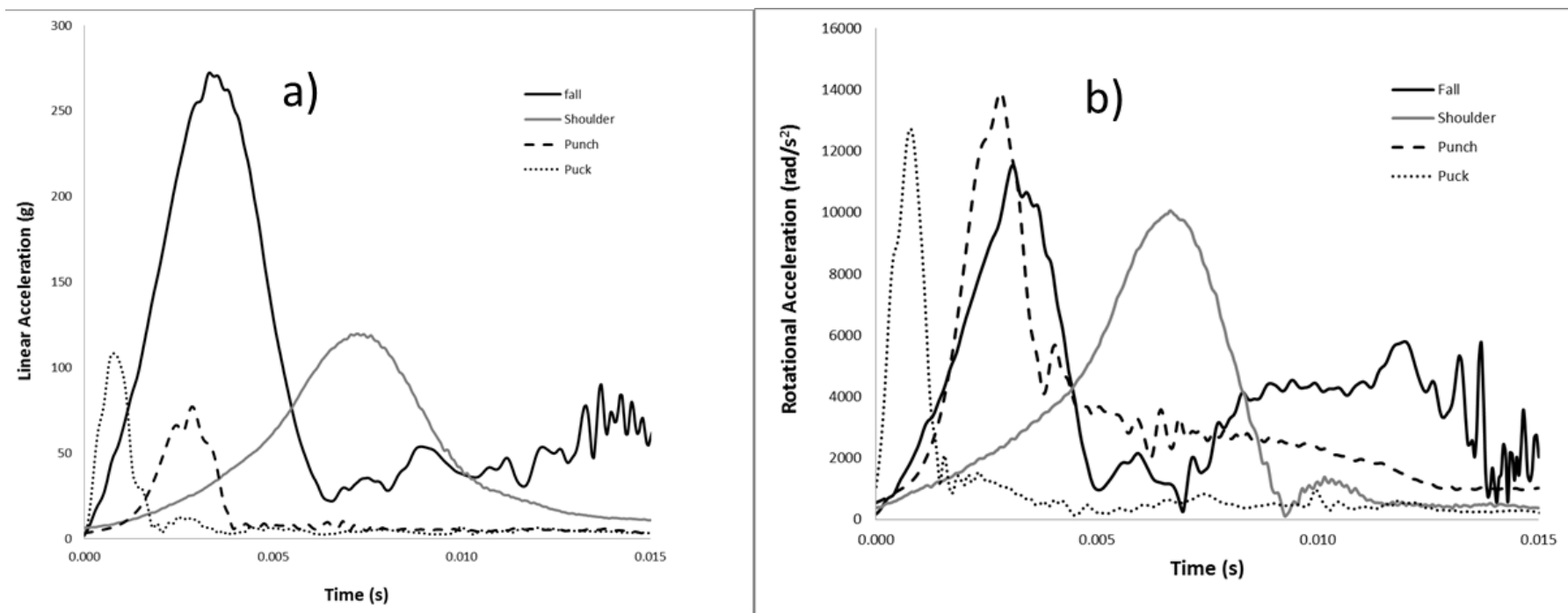

Figure 5: Linear (a) and rotational (b) acceleration time histories representing the typical curve Characteristics for risk of brain injury for different mechanisms; falls to ground, shoulder/elbow $(12 \mathrm{~kg})$, and punch $(2 \mathrm{~kg})$ at $6.5 \mathrm{~m} / \mathrm{s}$, and puck projectile $(0.166 \mathrm{~kg})$ at $34 \mathrm{~m} / \mathrm{s}$. 
Citation: Hoshizaki B, Post A, Kendall M, Karton C, Brien S (2013) The Relationship between Head Impact Characteristics and Brain Trauma. J Neurol Neurophysiol 5: 181. doi:10.4172/2155-9562.1000181

it is unlikely that a traumatic brain injury would occur in a sporting collision involving a helmet.

\section{Punches}

Brain injuries resulting from punches are characterized by lower effective mass (arm and hand) coupled with high impact velocities when compared to falls and collisions [31]. Research involving professional boxers reported mean impact velocities of the impacting fist to be9.1 (2.1) $\mathrm{m} / \mathrm{s}$ with an effective mass of only $2.9(2.0) \mathrm{kg}$ [73]. This type of impact mechanism shows that effective punch mass is low where differences among individuals are minor. In addition, the compliance of the fist/glove is considerably higher than other mechanisms of injury such as falling onto concrete. For brain injury to occur under these conditions, it is likely that the velocity and location of the impact play a more significant role than mass and compliance. Non-centric impacts, vectors outside the center of gravity of the head, cause high rotational responses and subsequently higher levels of brain strains [46,74]. Typically punches that result in concussions involve impacting locations such as the jaw region, which creates high rotational accelerations [31] (Table 2). As a result when a person incurs a concussive injury from a punch the location of impact of the fist will greatly influence the outcome of the impact event. A punch straight to the face will have a lower risk of concussion when compared to a punch that contacts the jaw and moves the head in a sideways fashion.

\section{Projectiles}

Injuries caused by projectiles typically include impacts where the head is hit with high velocity baseballs or hockey pucks. These impacts produce very short duration linear and rotational acceleration pulses through the brain tissue as a result of the very high velocity of the projectile object(approx. 35-40 m/s) [75] (Figure 5). If a helmet is not worn, these cases frequently incur skull fracture due to high forces applied to the skull over a small contact area. The resulting acceleration pulses are very short duration $(<5 \mathrm{~ms})$ with high magnitude reflective of the velocities and stiffness (low compliance) of baseballs and hockey pucks. The velocity of impact must be high for an individual to incur an injury from a low mass projectile (baseball, hockey puck) to get the energy high enough to cause injury. When the mass of the projectile is higher (boulder) then the velocity can be lower to cause a concussion or TBI.

\section{Future Directions}

Recent scientific evidence supports the notion that concussion injuries are much more complex than first described. Describing the factors that characterize this complexity is important in developing more effect prevention, diagnosis and treatment strategies. Research that serves to provide a better understanding of the relationship between the event or accident and the injury will serve to identify opportunities to decrease the risk of injury and lessen the social, psychological and financial burden on society. More recent evidence involving the association of low level repetitive brain trauma and lifelong neurological conditions is disturbing and deserves the attention of neurotrauma scientists.

\section{Conclusion}

The objective of this paper was to provide an understanding of the relationship between head impact parameters and brain trauma associated with head injuries. The limited knowledge describing both traumatic brain injuries as well as concussions makes it challenging to provide precise parameters predicting the severity of the injury. While evidence is presented in this paper that supports the notion that there is a continuum of injury severity it is not in any way conclusive and deserves continuing attention from the scientific community. It is clear from the reported research that the mechanism resulting in the injury is an important predictor of the risk of injury and likely associated with the severity and character of the injury. The intention of this paper was to provide a back ground of research in this area with the intention of generating discussions for future research.

\section{References}

1. Bain AC, Meaney DF (2000) Tissue-level thresholds for axonal damage in an experimental model of central nervous system white matter injury. J Biomech Eng 122: 615-622.

2. Monson KL, Goldsmith W, Barbaro NM, Manley GT (2003) Axial mechanical properties of fresh human cerebral blood vessels. J Biomech Eng 125: 288294.

3. Cater HL, Sundstrom LE, Morrison B 3rd (2006) Temporal development of hippocampal cell death is dependent on tissue strain but not strain rate. $J$ Biomech 39: 2810-2818.

4. King Al, Yang KH, Zhang L, Hardy W, Viano DC (2003) Is head injury caused by linear or angular acceleration? Proceedings of the IRCOBI Conference, Lisbon, Portugal, 1-12.

5. Zhang L, Yang KH, King Al (2004) A proposed injury threshold for mild traumatic brain injury. J Biomech Eng 126: 226-236.

6. Kleiven $S$ (2007) Predictors for traumatic brain injuries evaluated through accident reconstructions. Stapp Car Crash J 51: 81-114.

7. Post A, Hoshizaki TB, Gilchrist MD, Brien S (2012) Analysis of the influence of independent variables used for reconstruction of a traumatic brain injury event. Journal of Sports Engineering and Technology 226: 290-298.

8. Post A (2013) The influence of dynamic response characteristics on traumatic brain injury. University of Ottawa, Canada.

9. Meaney DF, Smith DH (2011) Biomechanics of concussion. Clin Sports Med 30: 19-31, vii.

10. McKee AC, Gavett BE, Stern RA, Nowinski CJ, Cantu RC, et al. (2010) TDP-43 proteinopathy and motor neuron disease in chronic traumatic encephalopathy. J Neuropathol Exp Neurol 69: 918-929.

11. Oeur A, Karton C, Post A, Rousseau, P, Hoshizaki TB, et al. (2013) An examination of headform dynamic response for concussive and traumatic brain injuries.

12. Langlois JA, Rutland-Brown W, Thomas KE (2010) Traumatic Brain Injury in the United States: Emergency Department Visits, Hospitalizations, and Deaths. Atlanta: Centers for Disease Control and Prevention, National Center for Injury Prevention and Control.

13. Tagliaferri F, Compagnone C, Korsic M, Servadei F, Kraus J (2006) A systematic review of brain injury epidemiology in Europe. Acta Neurochir (Wien) 148: 255-268.

14. Stevens JA, Corso PS, Finkelstein EA, Miller TR (2006) The costs of fatal and non-fatal falls among older adults. Inj Prev 12: 290-295.

15. Blatter DD, Bigler ED, Gale SD, Johnson SC, Anderson CV, et al. (1995) Quantitative volumetric analysis of brain MR: normative database spanning 5 decades of life. AJNR Am J Neuroradiol 16: 241-251.

16. Scahill RI, Frost C, Jenkins R, Whitwell JL, Rossor MN, et al. (2003) A longitudinal study of brain volume changes in normal aging using serial registered magnetic resonance imaging. Arch Neurol 60: 989-994.

17. Ji S, Zhu Q, Dougherty L, Margulies SS (2004) In vivo measurements of human brain displacement. Stapp Car Crash J 48: 227-237.

18. Prange MT, Margulies SS (2002) Regional, directional, and age-dependent properties of the brain undergoing large deformation. J Biomech Eng 124: 244252.

19. Monea AG, Verpoest I, Vander Sloten J, Van der Perre G, Goffin J, et al (2012) Assessment of relative brain-skull motion in quasistatic circumstances by magnetic resonance imaging. J Neurotrauma 29: 2305-2317. 
Citation: Hoshizaki B, Post A, Kendall M, Karton C, Brien S (2013) The Relationship between Head Impact Characteristics and Brain Trauma. J Neurol Neurophysiol 5: 181. doi:10.4172/2155-9562.1000181

20. Post A, Hoshizaki TB (2012) Mechanical properties describing brain impact injuries: A review. Trauma 14: 327-349.

21. Gurdjian ES (1975) Re-evaluation of the biomechanics of blunt impact injury of the head. Surg Gynecol Obstet 140: 845-850.

22. Bradshaw DR, Ivarsson J, Morfey CL, Viano DC (2001) Simulation of acute subdural hematoma and diffuse axonal injury in coronal head impact. J Biomech 34: 85-94.

23. Kleiven S (2003) Influence of impact direction on the human head in prediction of subdural hematoma. J Neurotrauma 20: 365-379.

24. Gennarelli TA, Abel JM, Adams H, Graham D (1979) Differential Tolerance of Frontal and Temporal Lobes to Contusion Induced by Angular Acceleration. Proceedings of Stapp Car Crash Conference 23: 563-586.

25. Gennarelli TA, Thibault LE, Adams JH, Graham DI, Thompson CJ, et al. (1982) Diffuse axonal injury and traumatic coma in the primate. Ann Neurol 12: 564 574

26. Al-Bsharat AS, Hardy WN, Yang KH, Khalil TB, Tashman S, et al. (1999) Brain/skull relative displacement magnitude due to blunt head impact: New experimental data and model. Proceedings of the 43rd Stapp Car Crash Conference SAE 99SC22.

27. Zhou C, Khalil TB, King Al (1995) A new model for comparing responses of the homogeneous and inhomogeneous human brain. In: Proceedings of the 39th Stapp Car Crash Conference, 121-136.

28. Gurdjian ES (1976) Cerebral contusions: re-evaluation of the mechanism of their development. J Trauma 16: 35-51.

29. Gennarelli TA, Thibault L, Tomei G, Wiser R, Graham D (1987) Directional dependence of axonal brain injury due to centroidal and non-centroidal acceleration. Proceedings in the 31stStapp Car Crash Conference: 49-53.

30. Post A, Hoshizaki TB, Gilchrist MD, Brien S, Cusimano MD, et al. (2013) The influence of dynamic response and brain deformation metrics on the occurrence of subdural hematoma in different regions of the brain. $\mathrm{J}$ Neurosurg

31. Kendall M, Post A, Rousseau P, Oeur A, Gilchrist M, et al. (2012) A comparison of dynamic impact response and brain deformation metrics within the cerebrum of head impact reconstructions representing three mechanisms of head injury in ice hockey. Proceedings of the IRCOBI conference in Dublin, Ireland.

32. Cassidy JD, Carroll LJ, Peloso PM, Borg J, von Holst H, et al. (2004) Incidence, risk factors and prevention of mild traumatic brain injury: results of the who collaborating centre task force on mild traumatic brain injury. Journal of Rehabilitation Medicine Suppl. 43: 28-60.

33. Cantu RC (1992) Cerebral concussion in sport. Management and prevention. Sports Med 14: 64-74.

34. McCrory P, Meeuwisse W, Johnston K, Dvorak J, Aubry M, et al. (2009) Consensus Statement on Concussion in Sport: the 3rd International Conference on Concussion in Sport. British Journal of Sports Medicine 21: i76-90.

35. Makdissi M, Cantu RC, Johnston KM, McCrory P, Meeuwisse WH (2013) The difficult concussion patient: what is the best approach to investigation and management of persistent (>10 days) postconcussive symptoms? $\mathrm{Br} \mathrm{J}$ Sports Med 47: 308-313.

36. Blinman TA, Houseknecht E, Snyder C, Wiebe DJ, Nance ML (2009) Postconcussive symptoms in hospitalized pediatric patients after mild traumatic brain injury. Journal of Pediatric Surgery 44: 1223-1228.

37. Binder LM, Rohling ML, Larrabee GJ (1997) A review of mild head trauma. Part I: Meta-analytic review of neuropsychological studies. J Clin Exp Neuropsychol 19: 421-431.

38. Kelly JP, Rosenberg JH (1997) Diagnosis and management of concussion in sports. Neurology 48: 575-580.

39. McClincy MP, Lovell MR, Pardini J, Collins MW, Spore MK (2006) Recovery from sports concussion in high school and collegiate athletes. Brain Inj 20: 33-39.

40. Alves W, Macciocchi SN, Barth JT (1993) Postconcussive symptoms after uncomplicated mild head injury. Journal of Head Trauma Rehabilitation 8: 4859

41. Zanetti K, Post A, Karton C, Kendall M, Hoshizaki TB, et al. (2013) Identifying risk profiles for three player positions in American football using physical and finite element modeling reconstructions. Proceedings of IRCOBI, Gothenburg, Sweden.
42. Elkin BS, Morrison B 3rd (2007) Region-specific tolerance criteria for the living brain. Stapp Car Crash J 51: 127-138.

43. Nicolle S, Lounis M, Willinger R (2004) Shear Properties of Brain Tissue over a Frequency Range Relevant for Automotive Impact Situations: New Experimental Results. Stapp Car Crash J 48: 239-258.

44. Forero Rueda MA, Cui L, Gilchrist MD (2011) Finite element modelling of equestrian helmet impacts exposes the need to address rotational kinematics in future helmet designs. Comput Methods Biomech Biomed Engin 14: 1021 1031.

45. Post A Oeur A, Hoshizaki B, Gilchrist MD (2013) Examination of the relationship between peak linear and angular accelerations to brain deformation metrics in hockey helmet impacts. Comput Methods Biomech Biomed Engin 16: 511-519.

46. Post A, Oeur A, Hoshizaki TB, Gilchrist MD (2012) The Influence of Centric and Non-Centric Impacts to American Football Helmets on the Correlation Between Commonly Used Metrics in Brain Injury Research. International Research Council on Biomechanics of Injury Conference (IRCOBI), Dublin, Ireland.

47. McCrea M, Guskiewicz KM, Marshall SW, Barr W, Randolph C, et al. (2003) Acute effects and recovery time following concussion in collegiate footbal players - the NCAA Concussion Study. The Journal of the American Medical Association 290: 2556-2563.

48. Iverson G (2007) Predicting slow recovery from sport-related concussion: the new simple-complex distinction. Clinical Journal of Sports Medicine 17: 31-37.

49. Marshall S, Bayley M, McCullagh S, Velikonja D, Berrigan L (2012) Clinical practice guidelines for mild traumatic brain injury and persistent symptoms. Can Fam Physician 58: 257-267, e128-40.

50. Wright RM, Post A, Hoshizaki B, Ramesh KT (2013) A multiscale computationa approach to estimating axonal damage under inertial loading of the head. J Neurotrauma 30: 102-118.

51. Doorly MC, Gilchrist MD (2006) The use of accident reconstruction for the analysis of traumatic brain injury due to head impacts arising from falls. Comput Methods Biomech Biomed Engin 9: 371-377.

52. Wennberg RA, Tator $\mathrm{CH}$ (2003) National Hockey League reported concussions, 1986-87 to 2001-02. Can J Neurol Sci 30: 206-209.

53. Casson IR, Viano DC, Powell JW, Pellman EJ (2010) Twelve years of national football league concussion data. Sports Health 2: 471-483.

54. Nishizaki K, Marino W, Hoshizaki TB, Post A, Oeur A, et al. (2013) Evaluation of dynamic response and brain deformation metrics using a centric/noncentric impact protocol using a monorail impacting system. Journal of ASTM international.

55. Dewitt DS, Perez-Polo R, Hulsebosch CE, Dash PK, Robertson CS (2013) Challenges in the development of rodent models of mild traumatic brain injury. J Neurotrauma 30: 688-701.

56. Singh A, Lu Y, Chen C, Kallakuri S, Cavanaugh JM (2006) A new model of traumatic axonal injury to determine the effects of strain and displacement rates. Stapp Car Crash J 50: 601-623.

57. Thomas LM, Roberts VL, Gurdjian ES (1967) Impact-induced pressure gradients along three orthogonal axes in the human skull. J Neurosurg 26 316-321.

58. Post A, Oeur A, Hoshizaki TB, Gilchrist MD (2013) The influence of velocity on injury risk in American football. Proceedings of Helmet Performance and Design Conference.

59. Karton C, Hoshizaki TB, Gilchrist MD (2013) The influence of inbound mass on the dynamic impact response of the Hybrid III headform and tissue deformation response characteristics. Journal of ASTM international (In Press).

60. Cantu RC (1996) Head injuries in sport. Br J Sports Med 30: 289-296.

61. Powell JW (1998) The evolution of ice hockey related injuries in the NHL. In: Biasca N, Montag W-D, Gerber C, (eds.) Safety in ice hockey: IIHF International Symposium on Medicine and Science in Ice Hockey on the occasion of the 8th Ice Hockey World Championship. IIHF, Zurich 19-25.

62. Cusimano MD, Taback NA, McFaull SR, Hodgins R, Bekele TM, et al. (2011) Effect of bodychecking on rate of injuries among minor hockey players. Open Med 5: e57-64.

63. Emery CA, Kang J, Shrier I, Goulet C, Hagel BE, et al. (2010) Risk of injury associated with body checking among youth ice hockey players. JAMA 303 2265-2272. 
Citation: Hoshizaki B, Post A, Kendall M, Karton C, Brien S (2013) The Relationship between Head Impact Characteristics and Brain Trauma. J Neurol Neurophysiol 5: 181. doi:10.4172/2155-9562.1000181

64. Hagel BE, Marko J, Dryden D, Couperthwaite AB, Sommerfeldt J, et al. (2006) Effect of bodychecking on injury rates among minor ice hockey players. CMAJ 175: 155-160.

65. Honey CR (1998) Brain injury in ice hockey. Clin J Sport Med 8: 43-46.

66. Hutchison MG, Comper P, Meeuwisse WH, Echemendia RJ (2013) A systematic video analysis of National Hockey League (NHL) concussions, part I: who, when, where and what? British Journal of Sports Medicine (In Press).

67. Donaldson L, Asbridge M, Cusimano MD (2013) Bodychecking rules and concussion in elite hockey. PLoS One 8: e69122.

68. Zazryn TR, Finch CF, McCrory P (2003) A 16 year study of injuries to professional boxers in the state of Victoria, Australia. Br J Sports Med 37: 321324

69. Gartland S, Malik MH, Lovell ME (2001) Injury and injury rates in Muay Tha kick boxing. Br J Sports Med 35: 308-313.

70. Canadian Institute for Health Information (2006) Head injuries in Canada: A decade of change (1994-1995 to 2003-2004).
71. Styrke J, Stålnacke BM, Sojka P, Björnstig U (2007) Traumatic brain injuries in a well-defined population: epidemiological aspects and severity. J Neurotrauma 24: $1425-1436$.

72. Hoshizaki TB, Brien SE (2004) The science and design of head protection in sport. Neurosurgery 55: 956-966.

73. Walilko TJ, Viano DC, Bir CA (2005) Biomechanics of the head for Olympic boxer punches to the face. Br J Sports Med 39: 710-719.

74. Post A, Oeur A, Hoshizaki TB, Gilchrist MD (2012) On the importance of using a centric/non-centric protocol for the evaluation of ice hockey helmet performance. Proceedings of ASTM Symposium on the mechanism of concussion in sports. Atlanta, GA, USA.

75. Rousseau P, Hoshizaki TB, Gilchrist MD (2012) Protective capacity of ice hockey player helmets against puck impacts. Proceedings in ASTM Symposium on the mechanism of concussion in sports. Atlanta, GA, USA. 